\title{
PEDAGOGIA VISUAL NA EDUCAÇÃO DE SURDOS: ANÁLISE DOS RECURSOS VISUAIS INSERIDOS EM UM LDA
}

\author{
VISUAL PEDAGOGY IN THE EDUCATION OF THE DEAF: ANALISIS OF \\ THE VISUAL RESOURCES INSERTED IN AN ADT
}

\section{PEDAGOGÍA VISUAL EN LA EDUCACIÓN PARA SORDOS: ANÁLISIS DE RECURSOS VISUALES INSERTADOS EN UM LDA}

Ellen Midiã Lima da Silva Gomes ${ }^{1}$ Flávia Faissal de Souza ${ }^{2}$

\begin{abstract}
RESUMO
O texto discute o papel dos recursos da pedagogia visual, inseridos em um livro didático digital acessível (LDA), enquanto dispositivos de acessibilidade ao conteúdo pensado para alunos surdos matriculados em duas turmas de $3^{\circ}$ ano do Ensino Fundamental I de uma escola pública de Duque de Caxias que adota como proposta pedagógica o bilinguismo. Este estudo parte do princípio de que as práticas pedagógicas embasadas na experiência visual contribuem para um melhor aprendizado de alunos surdos. A metodologia desta pesquisa embasou-se na perspectiva histórico-cultural, com viéis da pesquisa participante. Participaram do estudo 3 professoras da educação básica e 4 alunos surdos. Os resultados apontaram que: devido à aquisição tardia da língua de sinais os alunos tiveram dificuldades para compreender a Libras da janela em Libras, sendo necessária a mediação pedagógica; o uso de vídeos e ilustrações embasados na pedagogia visual contribuiu para a compreensão do conteúdo pelos alunos; apesar dos recursos da pedagogia visual no LDA, as estratégias de mediação entre alunos e professoras foram fundamentais para que os conteúdos ganhassem significado, como o uso de objetos pedagógicos e do próprio corpo. Assim, este estudo revelou que o LDA isoladamente não promoveu significado para os alunos surdos, sendo necessário o uso de estratégias de mediação a partir das
\end{abstract}

Submetido em: 14/03/2020 - Aceito em: 13/04/2020 - Publicado em: 29/04/2020.

${ }^{1}$ Licenciada em Pedagogia pela Universidade UNIGRANRIO (2016), Mestre em Educação, Cultura e Comunicação em Periferias Urbanas - UERJ/FEBF (2019).

${ }^{2}$ Licenciada plena em Educação Física pela Universidade do Estado do Rio de Janeiro (1993), Especialização em Educação Física junto a Pessoas Portadoras de Deficiência pela Universidade Federal de Uberlândia (1997), mestrado e doutorado em Educação pela Universidade Estadual de Campinas (respectivamente: 2001 e 2013) e Pósdoutorado junto ao Programa de Pós-graduação em Educação, Demandas Populares e Contextos Contemporâneos (PPGEduc/IM/UFRRJ). 


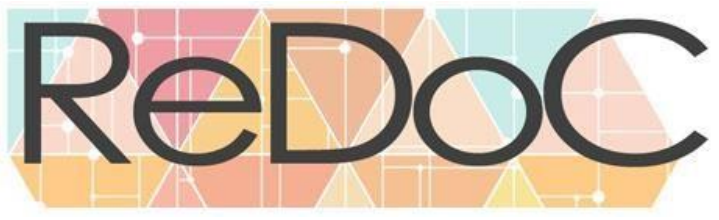

Revista Docência e Cibercultura

interações entre alunos e professores.

Palavras-chave: Pedagogia visual. Educação de surdos. Livro Digital Acessível.

\begin{abstract}
The text discusses the role of visual pedagogy resources, inserted in a accessible digital textbook (ADT), as accessibility devices to the content designed for deaf students enrolled in two classes of $3^{\text {rd }}$ years of Elementary School in a public school in Duque de Caxias which adopts bilingualism as its pedagogical proposal. This study is based on the principle that pedagogical practices based on visual experience contribute to better learning for deaf students. The methodology of this research was based on the historical-cultural perspective, with participant research strands. The study included 3 teachers and 4 deaf students of primary school. The results pointed out that: due to the late acquisition of sign language the students had difficulties to understand Libras from the window in Libras, being necessary the pedagogical mediation; the use of videos and illustrations based on visual pedagogy contributed to the comprehension of the content by the students; despite the resources of visual pedagogy in the ADT, mediation strategies between students and teachers were fundamental for the contents to gain meaning, such as the use of pedagogical objects and the body itself. Thus, this study revealed that ADT alone did not promote meaning for deaf students, requiring the use of mediation strategies from interactions between students and teachers.
\end{abstract}

Keywords: Visual pedagogy. Education of the deaf. Accessible Digital Textbook.

\title{
RESUMEN
}

El texto discute el papel de los recursos de pedagogia visual insertados en un libro digital accesible (LDA), como dispositivos de accesibilidad al contenido diseñado para estudiantes sordos matriculados en dos clases de 3er año de primaria en una escuela pública en Duque de Caxias que adopta el bilinguismo como una propuesta pedagógica. Este estudio se basa en el principio de que las prácticas pedagógicas basadas en el experiência visual contribuyen a un mejor aprendizaje para los estudiantes sordos. La metodología de esta investigación se baso en la perspectiva histórico-cultural, con la orientación de la investigación participante. 3 profesoras de educación básica y 4 estudiantes sordos participaron en el estudio. Los resultados mostraron que: debido a la adquisición tardía del lenguaje de señas, los estudiantes tenían dificultades para compreender janela en Libras, lo que requería una mediación pedagógica; el uso de vídeos e ilustraciones basados en pedagogia visual contribuyó a la comprensión del contenido por partes de los estudiantes; a pesar de los recursos de la pedagogía visual en LDA, las estrategias de mediación entre estudiantes y maestros fueron fundamentales para que el contenido adquiriera significado, como el uso de objetos pedagógicos y el propio cuerpo. Por lo tanto, este estudio revelo que la LDA pó si sola no promovióel significado para los estudiantes sordos, requeriendo el uso de estratégias de mediación basadas en las interaciones entre estudiantes y maestros.

Palabras clave: Pedagogía visual. Educación para sordos. Libro Digital Accesible 


\section{Revista Docência e Cibercultura}

\section{INTRODUÇÃO}

O presente texto é um recorte de uma dissertação de Mestrado na área de Educação, que teve como foco central o debate sobre o papel dos recursos visuais, pensados com base nos princípios da pedagogia visual, elaborados para composição de um livro didático digital acessível, como suporte de acesso ao conteúdo pelos alunos surdos. Essa problemática se fundamenta na ideia de que, em geral, os livros didáticos utilizados na escolarização dos alunos surdos são estruturados a partir da língua portuguesa na modalidade escrita sendo que a primeira língua do surdo no Brasil é a Língua Brasileira de Sinais (Libras), o que dificulta o aluno surdo acessar o conteúdo do livro.

De tal forma, nossa problematização está estruturada em três eixos centrais, a saber: a língua de sinais como língua gesto-visual; as dificuldades educacionais no processo de ensino e aprendizagem de alunos surdos; e, os pressupostos da pedagogia visual.

Como é sabido, a língua de sinais é uma língua gesto-visual sendo realizada através de movimentos do corpo, das mãos, pelas expressões faciais e corporais. Apesar da sinalização ser percebida pela visão, esta apresenta as mesmas características de uma língua oral, contendo versatilidade e flexibilidade, arbitrariedade, criatividade e dupla articulação (HARRISON, 2014, p.23).

No Brasil, a legalização da Língua Brasileira de Sinais (Libras) ocorreu com a Lei 10. 436, de 24 de abril de 2002, quando a Libras passa a ser reconhecida como língua nacional que apresenta uma gramática própria e a visualidade. Esta lei foi regulamentada pelo Decreto $\mathrm{n}^{\mathrm{o}}$ 5.626, de dezembro de 2005, legitimando em seu Artigo $2^{\mathbf{o}}$, que a pessoa surda compreende e interage com o mundo através de experiências visuais, tendo a língua de sinais como uma das principais formas de manifestação cultural (BRASIL, 2005).

Este reconhecimento foi importante para o ensino de surdos porque a língua de sinais apresenta em sua gênese a visualidade, sendo a experiência visual fundamental para o processo de ensino e aprendizagem desses alunos, pois a todo momento, a visualidade, esta sendo experenciada por eles. Para Skliar (2001, p.176):

[...] a experiência visual dos surdos envolve, para além das questões linguísticas, todo tipo de significações comunitárias e culturais, exemplificando: os surdos utilizam apelidos ou nomes visuais; metáforas 


\section{Revista Docência e Cibercultura}

visuais; imagens visuais, humor visual; definição das marcas do tempo a partir de figuras visuais, entre tantas outras formas de significações.

O segundo eixo diz respeito a uma questão bastante discutida atualmente que são as dificuldades educacionais no processo de ensino e aprendizagem de alunos surdos. Tomando como pressupostos centrais alguns princípios da perspectiva histórico-cultral de desenvolvimento humano, assumimos que a aprendizagem não depende unicamente do aparato biológico, antes está relacionada ao modo como o sujeito participa e se apropria das práticas sociais (SMOLKA, 2014). Fontana (1996) reitera essa ideia ao afirmar que a escolarização é mediada socialmente pelo professor e pelos alunos com seus pares, sendo que é no decorrer das relações sociais que os sujeitos se apropriam dos conhecimentos presentes na sociedade em que vivem.

Assim, o uso de metodologias descontextualizadas das especificidades dos alunos surdos geram dificuldades no processo de ensino e aprendizagem, não indo ao encontro às necessidades deste público, uma vez que possuem como primeira língua (L1) a Libras que é uma língua gestovisual (LACERDA, 2016).

Para além dessas questões, Freitas (2016), ainda chama atenção para o uso dos livros didáticos tradicionais que em sua grande maioria se mostram inadequados para este público, dando ênfase a língua portuguesa e sem recursos visuais que atendam às demandas desses alunos.

Nessa esteira, o terceiro eixo aponta para a importância da pedagogia visual nesse processo, posto que esta é uma prática educacional que lança mão da visualidade, tendo o signo visual como base do processo de ensino e aprendizagem (CAMPELLO, 2008). O que nos instiga a pensar na potencialidade da pedagogia visual no processo de ensino e aprendizagem dos alunos surdos.

Lima (2010) aponta que a permanência dos alunos surdos no espaço escolar vai além de matriculá-los na escola e tratá-los com afeto e empatia. Antes, é fundamental para o processo de escolarização que estes alunos se sintam participantes do processo educacional, sendo respeitados como surdos que estão imersos em um mundo que é culturalmente visual.

Assim, a utilização de uma pedagogia visual contribui para a formulação de metodologias adequadas para as necessidades desses estudantes, valorizando a visualidade e buscando novas 


\section{Revista Docência e Cibercultura}

formas de apresentar o conteúdo trabalhado.

Isto posto, a pedagogia visual se refere a uma prática que se utiliza dos elementos da cultura surda e da língua de sinais como:

Contação de história ou estória, jogos educativos, envolvimento da cultura artística, cultura visual, desenvolvimento da criatividade plástica, visual e infantil das artes visuais, utilização da SignWriting (escrita de sinais) na informática, recursos visuais, sua pedagogia crítica e suas ferramentas e práticas, concepção do mundo através da subjetividade e objetividade com as "experiências visuais" (CAMPELLO, 2008, p. 129).

Frente ao exposto, este texto discute o papel dos recursos da pedagogia visual, inseridos em um livro didático digital acessível (LDA), enquanto dispositivos de acessibilidade ao conteúdo pensado para alunos surdos matriculados em duas turmas de $3^{\circ}$ ano do Ensino Fundamental I de uma escola pública de Duque de Caxias que adota como proposta pedagógica o bilinguismo.

Este estudo está inserido em um projeto coletivo de pesquisa intitulado "Desenho Universal para a Aprendizagem: implementação e avaliação do protocolo do livro digital acessível"3. O objetivo central desse projeto coletivo foi "implementar e avaliar o protocolo de Desenho Universal para a Aprendizagem do Unicef para livros didáticos acessíveis na escolarização de alunos que constituem o público da Educação Especial incluídos em diferentes realidades educacionais" ${ }^{4}$ (PLETSCH et al, 2018, p.17). Para tal, foi desenvolvido um protótipo de um LDA $^{5}$, a partir dos quesitos estabelecidos pelo protocolo para a produção de livros digitais acessíveis proposto pelo Unicef.

Vale mencionar que o protocolo de acessibilidade do livro didático digital foi resultado de uma iniciativa liderada pelo Unicef em 2014, organizada no Brasil pelo Movimento Down. A

${ }^{3}$ Projeto coordenado pela prof ${ }^{\mathrm{a}} \mathrm{Dr}^{\mathrm{a}}$ Márcia Denise Pletsch.

${ }^{4}$ A realização deste projeto contou com os recursos de uma emenda parlamentar, e com o apoio da Fundação Carlos Chagas Filho de Amparo à Pesquisa do Estado do Rio de Janeiro (FAPERJ), por meio de Edital 4/2016.

${ }^{5}$ Livro embasado nas indicações de Borges e Forentini (OBEE, 2017). 


\section{Revista Docência e Cibercultura}

iniciativa internacional denominada "Inclusive, equitable, quality education for all" reuniu especialistas de diversos países da América Latina e Caribe para a elaboração de diretrizes para a produção de livros didáticos acessíveis em desenho universal. As orientações dessa iniciativa internacional serviram como princípios norteadores e diz respeito ao desenho universal ${ }^{6}$ aplicado a aprendizagem - DUA (MOVIMENTO DOWN, 2015; PLETSCH, 2017).

O protótipo do LDA utilizado neste estudo ancorou-se na perspectiva do Desenho Universal para a Aprendizagem (DUA). Nunes e Madureira (2015) apontam que o DUA apresenta três princípios:

1) múltiplos meios de envolvimento: compreender quais aspectos motivam os alunos para a aprendizagem, estabelecendo uma relação de afetividade entre professores e alunos e entre os próprios alunos;

2) múltiplos meios de representação: apresentar o conteúdo de múltiplas formas utilizando recursos pedagógicos, permitindo aos estudantes novas formas de compreender o assunto que está sendo abordado;

3) múltiplos meios de ação e expressão: entender como as crianças aprendem. Cada indivíduo expressa e utiliza mecanismos diferentes para dizer o que sabe.

Santos (2015) expõem que esses princípios estão interligados a três grandes redes: Redes de Reconhecimento, responsável pelo modo como os fatos são recolhidos; Redes Estratégicas, que planeja e executa as ações, auxiliando na organização das expressões e ideias e Redes Afetivas que "diz" como os estudantes são motivados a permanecerem engajados para a aprendizagem.

É importante destacar que o DUA busca novas formas e meios diferentes para que o ensino seja acessível a todos os alunos, possibilitando que um maior número de estudantes tenha um currículo que atenda suas especificidades (NUNES; MADUREIRA, 2015).

Apesar de reconhecermos a relevância dos recursos digitais acessíveis para a educação, nos preocupa o papel exacerbado que vem sendo dado as Tecnologias de Informação e Comunicação (TICs) e as Tecnologias Assistivas (TAs) no escopo da educação dos alunos com deficiência, conforme já apontado por Souza (2013, 2016), isto porque esses recursos por si só 


\section{Revista Docência e Cibercultura}

não promovem a educação.

\section{PRESSUPOSTOS METODOLÓGICOS: CONHECENDO O LOCAL DA PESQUISA}

Este estudo se caracteriza como uma pesquisa na perspectiva histórico-cultural (FREITAS, 2002; SOUZA, 2001), baseando-se no materialismo histórico-dialético que reconhece o ser humano como ser biológico e cultural. Assumindo as estratégias da pesquisa participante, que no âmbito educacional é um modo para que professores e pesquisadores possam ressignificar suas práticas pedagógicas, buscamos nesta investigação refletir sobre o processo de ensino e aprendizagem de alunos surdos, tendo a colaboração de professoras e dos alunos surdos em uma escola de Duque de Caxias (TRIPP, 2005).

Assim, para aproximação com o campo lançamos mão da observação participante, utilizando como formas de registros: filmagem, preenchimento de uma ficha de registro e anotações em diário de campo (BOGDA; BIKLEN, 1994). A aplicação do LDA ocorreu em duas turmas bilíngues do $3^{\circ}$ ano do Ensino Fundamental I, nas quais o processo de ensino era organizado tendo a Libras como L1 e o português escrito como L2.

A pesquisa de campo aconteceu após um encontro inicial na escola, quando foi decidido com a direção e professores que acompanharíamos uma turma de $3^{\circ}$ ano durante seis dias. Destes, quatro dias foram destinados a aplicação do LDA e dois dias para entrevistas com as professoras, além de uma entrevista com o diretor para levantamento de dados da escola ${ }^{7}$. A tabela abaixo apresenta a relação dos alunos que participaram da investigação:

$\begin{array}{cccc}\text { Nome (fictício) } & \text { Idade } & \text { Turma } & \text { Deficiência } \\ \text { Marcos } & 8 \text { anos } & 302 & \text { Surdez } \\ \text { Leandro } & 11 \text { anos } & 302 & \text { Surdez, deficiência física } \\ \text { Leonardo } & 8 \text { anos } & 302 & \text { Surdez } \\ \text { Elton } & 9 \text { anos } & 301 & \text { Surdez }\end{array}$

${ }^{7}$ Aprovado pelo Comitê de Ética da UFRRJ atendendo a resolução 466/12, com o número de processo 23267.00959/2017-76. 


\section{Revista Docência e Cibercultura}

Tabela 1: Alunos participantes do estudo Fonte: Gomes, 2019

Estes alunos são moradores do município de Duque de Caxias, dos quatro, dois apresentam surdez profunda e dois surdez moderada. A inserção desses alunos em classe bilíngue ocorre pela necessidade de aquisição da língua de sinais. De acordo com as professoras participantes do estudo, muitos alunos chegam à escola sem o conhecimento da Libras, sendo necessário essa mediação.

As três professoras que participaram do estudo são bilíngues e ministram as aulas em Libras. Lívia de 46 anos de idade atua na educação infantil e na classe multisseriada trabalhando especificamente com os alunos surdos. Márcia tem 57 anos de idade e atua há 23 anos com alunos surdos. Carla tem 54 anos de idade, leciona há 32 anos, sendo16 anos com alunos surdos. Apresentamos a seguir uma tabela com os dados das professoras:

\begin{tabular}{|c|c|c|}
\hline $\begin{array}{c}\text { Nome } \\
\text { (fictício) }\end{array}$ & Formação & Atuação na escola \\
\hline Carla & $\begin{array}{l}\text { Licenciada em Pedagogia, curso de interpretação } \\
\text { de Libras no Ines }\end{array}$ & Professora do $3^{\circ}$ ano \\
\hline Márcia & $\begin{array}{l}\text { Licenciada em Português, especialização em } \\
\text { Orientação e Supervisão Educacional, curso de } \\
\text { Libras oferecido pela prefeitura }\end{array}$ & Professora do $3^{\mathrm{a}}$ ano \\
\hline Lívia & $\begin{array}{l}\text { Licenciada em Pedagogia e em Fonoaudióloga, } \\
\text { especialista em Psicomotricidade e Educação } \\
\text { Especial, mestre em Informática da Educação } \\
\text { Tabela 2: Professoras participantes do estudo } \\
\text { Fonte: Gomes, } 2019\end{array}$ & $\begin{array}{l}\text { Professora de } \\
\text { informática }\end{array}$ \\
\hline
\end{tabular}

Os dados que serão apresentados aqui foram circunscritos ao tema gerador do conteúdo do $\mathrm{LDA}^{8}$ : o corpo humano e cuidados de saúde. Deste tema foram elencadas três vertentes: higiene, rotina e diversidade dos corpos (tipos de cabelo, cor de pele, sexo, etc). Nesse processo,

\footnotetext{
${ }^{8} \mathrm{O}$ conteúdo do protótipo do LDA foi um capítulo do livro "Porta Aberta: ciências humanas e da natureza" de 2015, para o $1^{\circ}$ ano ensino fundamental: anos iniciais (metodologia). O capítulo tinha como tema gerador o corpo humano e os cuidados com a saúde trabalhando as seguintes dimensões: partes do corpo, rotina diária e higiene.
} 


\section{Revista Docência e Cibercultura}

foi observado, a partir dos discursos dos alunos, como estas três esferas faziam parte de seu cotidiano, como eram apropriadas por eles e como se percebiam como seres humanos. Ou seja, o processo de construção e de análise dos dados teve como foco as situações vivenciadas na escola circunscritas à problemática de estudo levantada. Deste modo os recursos visuais foram o alvo de nossas análises, sendo as categorias construídas por meio da análise dos vídeos, transcrições, imagens e observação participante, além da ficha de registro.

A primeira etapa da construção e análise dos dados foi a leitura do caderno de campo e a transcrição dos vídeos. Todos os vídeos foram transcritos com base nos estudos de Vasconcellos (2017), traduzindo a sinalização em Libras para a escrita portuguesa. As transcrições foram realizadas na medida em que o vídeo era assistido. Primeiro foram transcritas as falas verbais para o registro escrito e os sinais em Libras em português para gramática de Libras. Desse momento é importante destacar que em vários episódios as professoras bilíngues falavam enquanto sinalizavam, para este tipo de forma de comunicação a transcrição foi realizada diretamente pela tradução da Libras para o português escrito (VASCONCELLOS, 2017). E, em um segundo momento, todos os registros em gramática de Libras foram traduzidos para o português escrito.

Por ser uma turma composta por alunos surdos e por ter adotado o paradigma bilinguista, durante a transcrição também destacamos o modo como os estudantes se expressavam corporalmente, como: o olhar, a expressão de dúvida, euforia e frustração ao realizar as atividades, dentre outras formas de expressão corpórea. Por exemplo:

04:02: Leandro - Olha para o livro e retoma o vídeo em Libras... O aluno copia o vídeo e faz os sinais que conhece em Libras: BERNAR... PEQUENO... IDADE 4, VISINHO, LIBRAS, NÃO CONHECER, ENTENDER.... MÃE, O QUÊ, HISTÓRIA... O aluno olha para a câmera faz o sinal de tudo bem, chama a professora Carla e repete o sinal, informando que entendeu (OBEE, 2018).

A segunda etapa da construção e análise dos dados foi o recorte dos vídeos (printscreen), na qual foram selecionadas as cenas (imagens) que davam visibilidade a significações, contextualizando o assunto abordado. Para Lebedeff (2010), a experiência visual do surdo é para além dos sinais utilizados na comunicação. A visualidade surda abrange nomes visuais (sinal que substitui o nome da pessoa), metáforas visuais, imagens e figuras visuais, dentre outras. Assim 


\section{Revista Docência e Cibercultura}

sendo, no meio escolar todas as formas de visualidade deveriam ser priorizadas ao se trabalhar com alunos surdos.

Analisando os vídeos (transcrições e imagens) e o diário de campo listamos os tipos de recursos visuais utilizados no decorrer da pesquisa pelos docentes e no LDA, como os alunos acessavam o conteúdo do LDA, construíam os conceitos e, nesse processo, também nos chamou atenção as estratégias de mediação pedagógicas provocadas pelos professores e pelos próprios alunos.

Outro instrumento utilizado para a construção e análise dos dados foi a ficha de registro. Esta continha duas etapas: ficha 1 e ficha 2 . A ficha 1 possuía informações sobre a inserção do LDA como: a) o modo de apresentação do livro didático digital - se este foi com demonstração ou não, se houve a exploração entre os pares e se os professores auxiliaram o processo; b) contextualização - Se ocorreu a relação do assunto abordado em sala com o apresentado no LDA e c) aceitação pelo aluno - se houve interesse, familiaridade ou estranhamento. Já aficha 2 buscava informações sobre a acessibilidade do LDA, esta foi dividida em duas etapas: a) Mediação - se houve a necessidade de mediação por parte dos professores e/ou pares para o manuseio do LDA; b) O uso e a linguagem apresentada no LDA.

Tendo como base os objetivos e os registros aqui já citados, após a realização das transcrições foram selecionadas no texto as falas que indicavam possíveis questões que davam indícios sobre a usabilidade dos recursos pautados pela pedagogia visual. Buscando dar visibilidade analítica, foram construídas as seguintes categorias: a) janela em Libras; b) vídeos e ilustrações.

A análise dos dados se deu por meio da análise microgenética e paradigma indiciário (embasado na semiótica). Nesse tipo de análise é realizado um trabalho minucioso, observando detalhadamente cada transcrições, anotações do caderno de campo, além das fotos e filmagens (como os sujeitos desta investigação eram surdos, as expressões corporais e faciais foram fundamentais para a construção dos dados) (GOÉS, 2000).

\section{ANÁLISE DOS DADOS: RECURSOS VISUAIS INSERIDOS NO LDA}

Os recursos visuais foram importantes para a implementação do LDA em sala de aula por 


\section{Revista Docência e Cibercultura}

ter como base a visualidade. Reiteramos que como a língua de sinais tem como característica a gesto-visualidade, o uso de recursos visuais no processo de ensino e aprendizagem é de grande valia, pois reconhece as especificidades dos surdos e permite um trabalho pedagógico diferenciado, que ao invés de se pautar no oralismo baseia-se no bilinguismo (LACERDA, 2014; CAMPELLO, 2008).

No LDA foram utilizados como recursos visuais: a janela em Libras, vídeos e ilustrações. A seguir apresentamos como estes foram implementados e como remetiam aos conteúdos inseridos no LDA.

\section{a) JANELA EM LIBRAS}

No trabalho de construção de estratégias de acessibilidade ao conteúdo do LDA, a partir do protocolo do Unicef (2017) foi necessário cumprir com alguns requisitos, como a implementação de janelas com vídeos em Libras. Esta ferramenta foi acrescida nos enunciados das atividades e nos textos explicativos, permitindo que o aluno surdo tivesse uma interpretação em Libras do texto em português. A janela em Libras usada no LDA, estava representada por um ícone com a imagem de duas mãos simulando o sinal de Libras. Para acessar a janela o usuário precisava clicar no ícone.

Vale lembrar que, a janela em libras quebra com a monotonia do livro tradicional que apresenta o conteúdo de forma estática e linear e tem a imagem apenas como um apêndice. $\mathrm{O}$ uso deste recurso possibilita a contextualização do assunto abordado (LEBDEFF, 2010).

Para análise dessa categoria, observamos como os alunos utilizaram a janela em Libras, se tiveram dificuldades para acessar este recurso e como este possibilitou o acesso ao conteúdo do livro. No processo de construção dos dados apontamos duas situações que mais nos chamou atenção e que vinham ao encontro nestas questões levantadas: i) O ícone da janela em Libras; ii) A linguagem utilizada na janela. Vejamos.

i) O ícone da janela em Libras 
Em relação ao ícone utilizado, inicialmente encontramos um problema, os estudantes do $3^{\circ}$ ano do Ensino Fundamental I tiveram dificuldades para abrir a janela em Libras, o ícone por si só não era suficiente para que os alunos entendessem que ali havia um vídeo em Libras explicando o assunto, com isso as professoras mostraram aos alunos como abrir a janela em Libras:

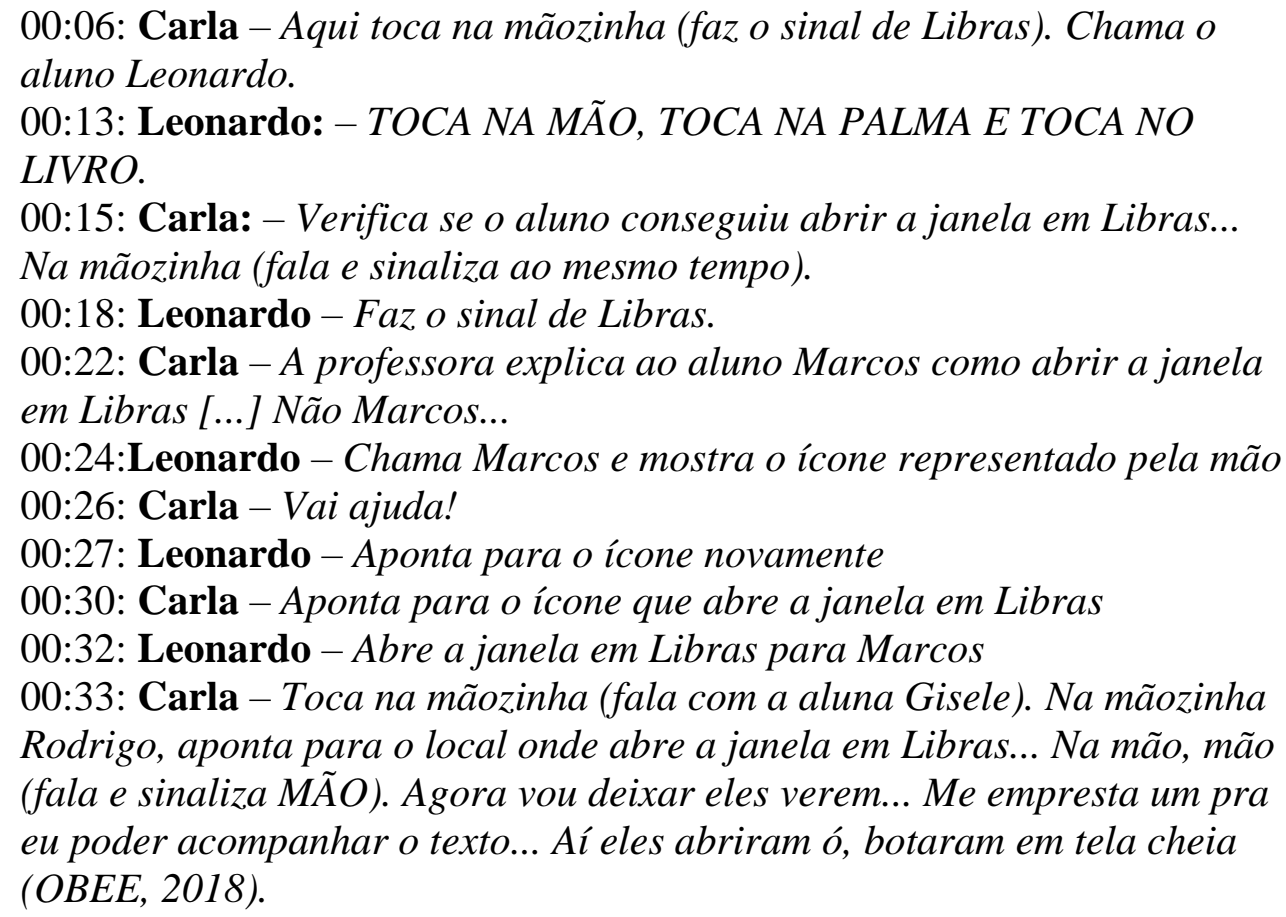

A figura a seguir mostra o momento em que um aluno abre a janela em Libras e amplia a tela. Como relatado acima, o aluno precisou da mediação da professora para ativar a janela em Libras.
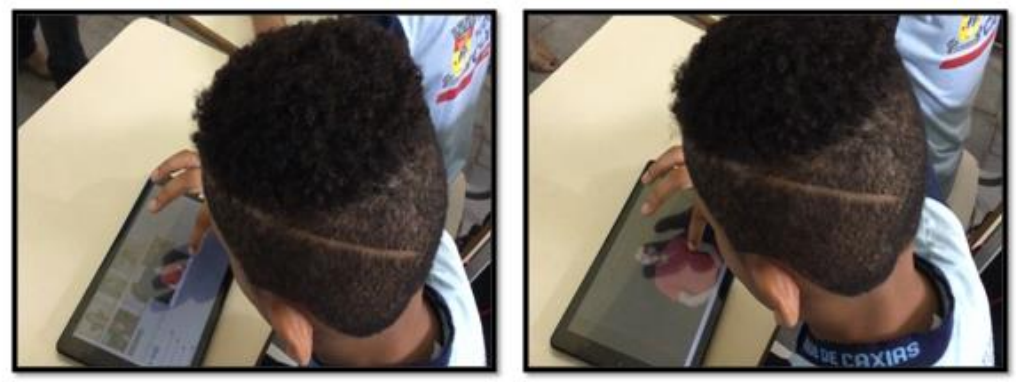

Figura 1: Aluno abrindo a janela em Libras

Fonte: Arquivo OBEE, 2018. 


\section{Revista Docência e Cibercultura}

Esse fato ocorreu porque os alunos não conheciam aquele símbolo, embora o símbolo seja considerado "universal" este não foi significado pelos alunos, sendo necessário que as professoras explicassem o que aquela imagem representava. Somente com a mediação das professoras que a imagem ganhou significado, tal fato, reforça a afirmação de Albres (2014, p.82): "É na interação com o outro, em um determinado contexto e tempo específico, que os sinais vão tomando significado".

Sobre a aprendizagem do ícone, Taveira (2015) tece importantes reflexões sobre a educação de surdos ao afirmar que no meio escolar os alunos surdos devem ser ensinados por meio de recursos visuais, esse processo é denominado como letramento visual. Ou seja, é por meio da observação das imagens, suas características que estes estudantes aprendem o que as imagens representam, o contexto que estão inseridas, compreendendo assim seus significados. Mesmo sendo um símbolo universal, ele só tem significado se apreendido pelo sujeito.

Essa situação, também nos levou a refletir sobre a ideia de que os implementos tecnológicos são de uso intuitivo para a geração que hoje está na escola. Aqui levantamos um ponto: a usabilidade da tecnológica não está impressa na matriz biológica humana, mas depende da aproximação prévia que o sujeito tem com equipamentos tecnológicos. Aqui cabe lembra a situação de pobreza e processos de exclusão de direitos que vivem os alunos que participaram desse estudo.

\section{ii) A linguagem utilizada na janela}

A linguagem utilizada na janela em Libras foi destaque no processo de construção de dados por revelar um problema bastante discutido por pesquisadores da surdez (LACERDA, 2014; MOURA, 2014; THOMA; LOPES, 2017), a aquisição tardia da língua de sinais. Para os autores os surdos precisam ter contato com a língua de sinais desde o nascimento e não apenas quando chegam à escola. 
Como já informado, a janela em Libras foi utilizada para explicar o enunciado das atividades e os textos, contudo, as crianças não conseguiram compreender os sinais e sua contextualização, sendo necessária a intervenção das professoras. Vemos claramente este ocorrido no exemplo a seguir.

$\mathrm{Na}$ realização da atividade que pedia para os alunos selecionar a parte do corpo utilizada para jogar futebol, os discentes não conseguiram entender o que estava sendo pedido. Na fala da professora:

Márcia - Essa pergunta aqui, do jeito que está ali ele não entende [...] Entendeu, aí você vê que só, os sinais ali não dá pra entender muito não.

A professora Márcia faz este comentário a partir da sua observação da turma. Na explicação do texto eles também tiveram dificuldade para compreender. Essa dificuldade foi vista em todos os alunos.

Ao perceber que os alunos não estavam entendendo a explicação em Libras do LDA, as professoras começaram a fazer perguntas sobre o vídeo $e$ pediam para que eles vissem a gravação novamente. Como os alunos estão em fase de aquisição da Libras muitos sinais não eram entendidos, assim as professoras pediam para que eles assistissem os vídeos e explicavam as palavras que estes não conheciam. Nos vídeos que tinham mais sinais conhecidos as professoras faziam perguntas mais fácies como a idade do personagem ou o nome (DIÁRIO, 2018).

Vejamos essa situação em sala de aula:

05:18: Carla - Ó... sinaliza para os alunos olharem para ela. Idade qual menino?Menino idade? Menino... BERNARDO, idade qual? Libras vídeo, viram Libras? Idade Qual? Eles viram a Libras, mas eles não prestaram atenção [...] Eles viram mas não prestaram atenção, nenhum dos quatro aqui. Menino idade qual?

06:00: Márcia - Agora eles se concentraram mais.

06:09: Carla - É? Então vou colocar pra ver de novo. Faz o sinal de... De novo... Ó, de novo (fala e sinaliza)... De novo, todo mundo do começo (fala com os estagiários) [...] Menino idade qual? Gisele idade 12, Marcos idade 8, Leonardo idade 8... A professora mostra a história no livro para Gisele e pergunta: Menino idade qual?

08:33: Gisele - Assiste mais uma vez e começa a sinalizar com o vídeo... menino idade 4

09:16: Carla - Ah (palmas em libras). Conseguiu! Aplausos...(OBEE, 2018). 


\section{Revista Docência e Cibercultura}

Para as professoras, esta dificuldade de compreensão se deu pela falta de domínio da língua de sinais por parte dos alunos. Segundo as professoras muitos estudantes chegam à escola sem saber a língua de sinais. A maioria dos alunos surdos, se não a totalidade, são filhos de pais ouvintes e só foram ter contato com a Libras na escola. Devido a essa necessidade os estudantes ao ingressarem na Educação Infantil ficam em classes bilíngues onde o ensino é realizado todo em Libras com o uso do português na modalidade escrita para que estes possam consolidar a língua de sinais.

Essa análise vai ao encontro dos estudos de Moura (2014) que reconhece que a criança surda precisa ter contato com a língua de sinais o mais cedo possível, sendo oportunizado a ela contato com a libras em diferentes espaços da sociedade, com diferentes assuntos, conhecendo assim as diferentes formas de expressão por meio da Libras.

Conforme as professoras insistiam para que os alunos vissem os vídeos várias vezes os estudantes começaram a reconhecer os sinais presentes na janela em Libras. Alguns chegavam a interagir com o vídeo em Libras como se estivessem conversando com o intérprete pessoalmente, vejamos o exemplo:

Durante a atividade para ligar às imagens das partes do corpo às palavras que representam essas partes, Leonardo aciona a janela em Libras para ver a explicação do exercício. Conforme assiste o vídeo em Libras o aluno demonstra entender a fala do intérprete e passa a conversar em Libras com o vídeo em libras:

Janela em libras - Você saber corpo partes saber qual?

Leonardo - Já Saber, conhecer.

Janela em libras - Saber partes nome ligar coluna ao lado. Ligar palavras parte corpo (IMG: 1565, 2018).

Contudo, a velocidade da Libras presente na janela dificultou a compreensão dos alunos e as professoras passaram a pausar o vídeo e explicar o assunto abordado. Isto nos faz refletir sobre algumas questões inerentes a educação de surdos: A presença de um intérprete de Libras garante que os alunos surdos irão aprender? O uso de tecnologias assistivas isoladamente promove de fato o aprendizado? Os dados desta pesquisa nos mostram que não.

O uso das tecnologias assistivas descontextualizadas e isoladas não promovem o aprendizado, como vimos no caso da janela em Libras. Para que a ferramenta ganhasse 


\section{Revista Docência e Cibercultura}

significado as professoras precisaram mediar todo o processo de uso, lançando mão de atividades que corroboravam para o entendimento do conteúdo.

Apesar da janela em Libras ter possibilitado o contato dos alunos com a língua de sinais este recurso por si só não possibilitou a compreensão do conteúdo. O que fez diferença foram os variados objetos pedagógicos visuais juntamente com o trabalho pedagógico. Assim, as estratégias de mediação das professoras foram fundamentais para que os alunos compreendessem o ícone e a ideia de que havia um vídeo em Libras no qual o conteúdo era sinalizado. Com esta resposta não estamos desvalorizando o trabalho do intérprete e nem menosprezando o uso das TIC's, antes afirmamos que estes isoladamente não promovem um ensino efetivo.

$\mathrm{Na}$ pesquisa realizada vimos que o conteúdo teve significado a partir do trabalho colaborativo das três professoras e da equipe de pesquisa, além das trocas dos alunos com seus pares.

\section{b) VÍDEOS E ILUSTRAÇÕES}

Outros recursos visuais inseridos no LDA foram os vídeos e ilustrações. Estes objetivavam atender as exigências do protocolo da Unicef possibilitando uma melhor compreensão do conteúdo presente no instrumento. Os vídeos abordavam questões sobre as partes do corpo, higiene e tipos de cabelo. A sequência dos fatos permitiu uma melhor compreensão dos assuntos abordados.

Retomando a usabilidade dos vídeos como recursos visuais inseridos no LDA vimos que o primeiro vídeo assistido pelos alunos foi “Little Baby Bum: cabeça, ombro, joelho e pé”. Os alunos demonstraram interesse pelo vídeo e alguns até dançaram quando perceberam que era uma música. Outros aproximaram o tablet da orelha e falavam que estavam ouvindo:

00:01: Carla - Esse aqui agora, pra eles verem esse videozinho. Eles queriam ver (falando com Márcia - vídeo cabeça, ombro, joelho e pé).

00:53: Leonardo - $O$ aluno sinaliza que está ouvindo a música do vídeo e coloca o tablete próximo a orelha de Marcos

00:55: Marcos - O aluno aproxima o rosto do tablete para ver se ouve a música. 


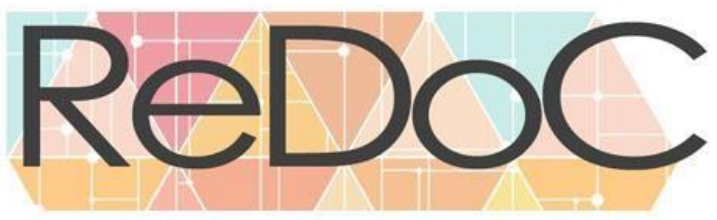

\section{Revista Docência e Cibercultura}

01:02: Carla - Aqui ouvindo... ó, ver vídeo, tudo bem? (OBEE, 2018).

A figura a seguir retrata o momento em que os alunos assistiram o vídeo "Little Baby Bum" referido acima.
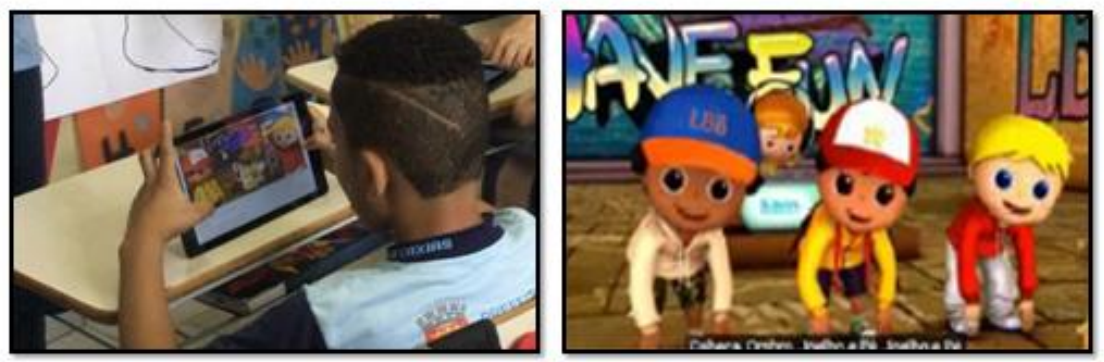

Figura 2: Vídeo partes do corpo humano

Fonte: Arquivo OBEE, 2018.

Devido ao caráter visual dos vídeos utilizados os alunos surdos não tiveram dificuldades de compreender. Para Skliar (1998) a potencialidade visual do surdo não se limita a língua de sinais. Para o autor a surdez é uma experiência visual, ou seja, "todos os mecanismos de processos da informação, e todas as formas de compreender o universo em seu entorno, se constituem como experiência visual" (p.28).

As ilustrações presentes no LDA, utilizadas como outro recurso, não foram escolhidas aleatoriamente. Estas buscavam dar visibilidade imagética ao texto escrito em português a fim de facilitar a compreensão do assunto tratado, como exemplificado na figura a seguir. 


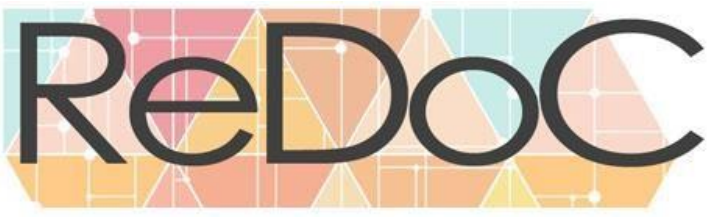

Revista Docência e Cibercultura

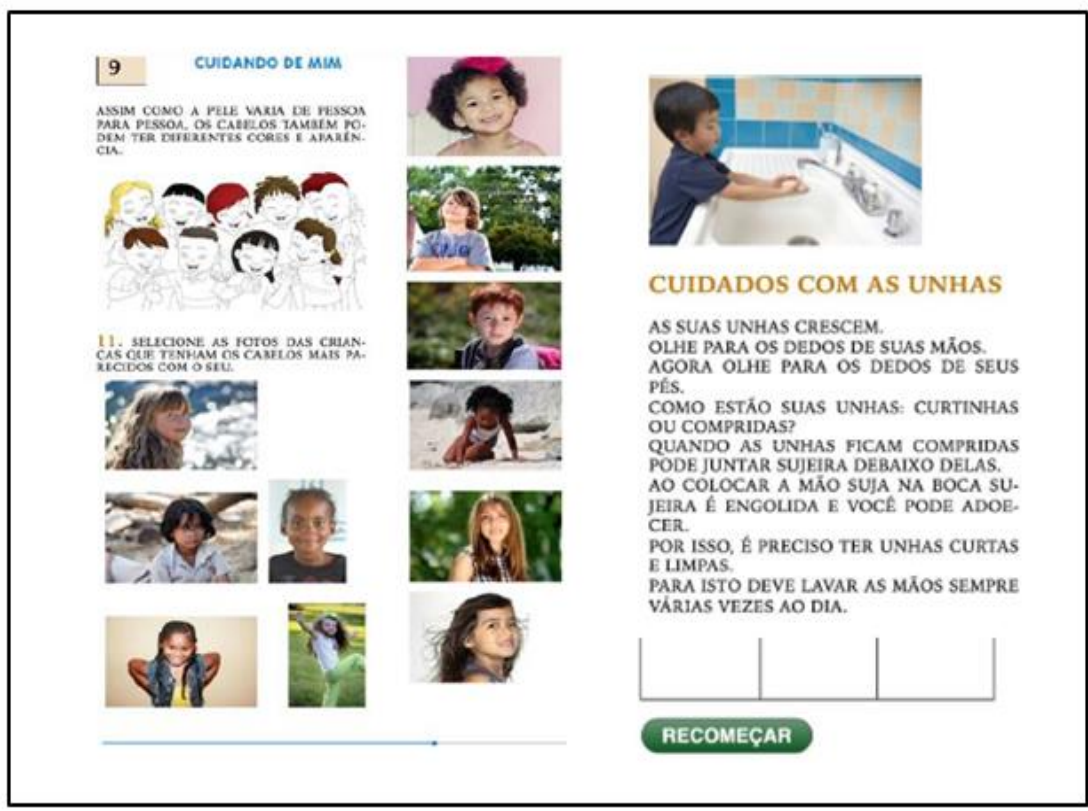

Figura 3: Imagens inseridas no LDA

Fonte: Arquivo OBEE, 2018.

Nem todas as atividades possuíam textos escritos, algumas apresentavam apenas o enunciado pedindo para selecionar quais imagens representava o que estava sendo solicitado. Como exemplo, a atividade na imagem acima que tratava sobre os diferentes tipos de pele e de cabelo, em que pedia que os alunos marcassem a imagem que mais se assemelhava a eles.

A partir deste exemplo vemos que a escola como instituição social, deve estabelecer com os alunos relações entre o conteúdo abordado em sala de aula com o que é vivido fora dela. Para os alunos surdos esta contextualização apresenta grande importância, pois muitos tiveram pouco contato com os falantes de sua língua, ocasionando assim dificuldades para assimilação dos conceitos (LACERDA; SANTOS; CAETANO, 2014).

Vigotski (1998) ainda ressalta que a aprendizagem é um processo social, sendo o diálogo e as diversas funções da linguagem fundamentais para o desenvolvimento cognitivo. $\mathrm{O}$ outro, no caso o professor, apresenta um papel fundamental, pois ele é responsável por estabelecer esse diálogo.

\section{CONSIDERAÇÕES FINAIS}

Buscando compreender a importância de uma pedagogia pensada para o ensino de alunos 
surdos, a partir dos pressupostos da pedagogia visual, vimos que esta metodologia faz uso de elementos visuais presentes na cultura surda e na língua de sinais contribuindo de forma mais significativa para o processo de ensino e aprendizagem de alunos surdos (CAMPELLO, 2008; BUZAR, 2009; LACERDA, 2014). Como a língua de sinais é uma língua gesto-visual, a não utilização de recursos visuais pode gerar dificuldades de aprendizagem a esses alunos.

Desta forma, compreendemos que parte dos problemas relacionados ao ensino de surdos ocorre pelo uso de materiais pedagógicos descontextualizados e que enfatizam o português não tendo um ensino pensado a partir do bilinguismo. Vale lembrar que a proposta do bilinguismo, como o nome já diz, não é o uso unicamente da língua de sinais, antes, reconhece a Libras como L1 do surdo e o português na modalidade escrita como L2 (CAMPOS, 2003).

A partir das análises dos dados vimos que os recursos visuais pensados com base na pedagogia visual inseridos no LDA atrelados a mediação pedagógica facilitou a compreensão do conteúdo pelos alunos, contextualizando as ideias que o texto abordava.

No que se refere ao LDA, o uso desta ferramenta precisa ser mediada pelos professores, pois seu emprego sem a devida intervenção não contribui para uma ação pedagógica significativa. Exemplo que vimos na utilização da janela em Libras. Isto não significa que este recurso é ineficiente, antes mostra a necessidade da ação do professor, pois ao utilizarem os recursos de acessibilidade presentes no LDA a relação professor e aluno foi fortalecia, permitindo um melhor aproveitamento dos conteúdos discutidos.

A realização desta pesquisa nos fez refletir sobre a necessidade de os surdos aprenderem a língua de sinais desde o nascimento e não apenas quando ingressam na escola. Os 4 alunos que participaram do estudo só passaram a ter contato com a Libras quando entraram na escola, isto fez com que eles tivessem dificuldades para compreender a Libras utilizada na janela em Libras. Moura (2014, p. 18) reitera essa necessidade de acesso à língua de sinais como L1 para os surdos:

O que é almejado é que a Libras seja a primeira língua da criança surda para que, estando ela em posse da mesma, possa se organizar como ser da linguagem e possa pensar, decidir, se constituir e organizar o mundo ao seu redor. O que se espera é que ela possa vir a ser um indivíduo funcional e fluente no seu ambiente, qualquer que seja ele: o doméstico, o profissional ou o das outras relações sociais. O que é necessário para que isso ocorra? Que a criança surda esteja cercada pela linguagem todo o tempo. 


\section{Revista Docência e Cibercultura}

Compreendemos que esta pesquisa pode inspirar outras investigações quanto ao uso da pedagogia visual para a educação de surdos, reconhecendo a importância do bilinguismo e da valorização das especificidades da cultura surda. Como também a utilização de práticas pensadas para todos os alunos da escola, possibilitando o acesso ao currículo a todos.

\section{REFERÊNCIAS}

ALBRES, N. de A. A construção dos sinais e sua mobilidade específica. In: LACERDA, C. B. F. de; SANTOS, L. F. dos. (Org.) Tenho um aluno surdo, e agora? Introdução à Libras e educação de surdos. São Carlos: Edufscar, 2014. p. 81 - 98.

ALMEIDA, S. D' A. Atendimento educacional especializado: análise das concepções de bilingüismo por profissionais da Escola Municipal Santa Luzia em Duque de Caxias/RJ. 2014. Dissertação (Mestrado em educação) - Universidade Federal Rural do Rio de Janeiro, Nova Iguaçu, 2014.

ARAÚJO, C. C. M; LACERDA, C. B. F. Atividades simbólicas e o desenvolvimento inicial da escrita da criança surda bilíngue. In BERBERIAN, A. P; ANGELIS, C. M; MASSI, G (Orgs), Letramento: referencias em saúde e educação São Paulo: Plexus, 2006. p. 221- 243.

BOGDA, R.; BIKLEN, S. K. Investigação qualitativa em educação: uma introdução à teoria e aos métodos, Porto, Portugal, Porto editora, 1994. (Coleção ciências da educação).

BUZZAR, E. A. S. Asingularidadevisuo-espacial do sujeito surdo: implicações educacionais. 2009. 122 f. Dissertação (Mestrado em Educação) - Universidade de Brasília, Brasília, 2009.

BRASIL. Decreto n. 5.626, de 22 de dezembro de 2005. Regulamenta a Lei no 10.436, de 24 de abril de 2002, que dispõe sobre a Língua Brasileira de Sinais - Libras, e o art. 18 da Lei no 10.098, de 19 de dezembro de 2000. Disponível em:<http://www.planalto.gov.br/ccivil_03/_Ato20042006/2005/Decreto/D5626.htm>. Acesso em 10 abr. 2018.

CAMPELlO, Ana Regina e Souza. Aspectos da visualidade na educação de surdos. 2008. Tese (Doutorado) - Universidade Federal de Santa Catarina, 2008. 


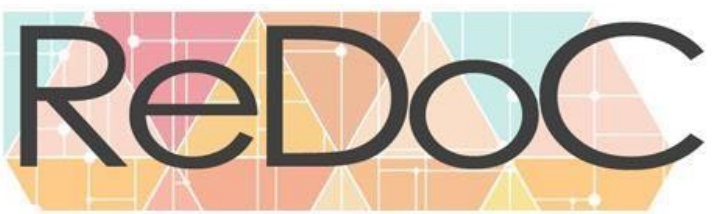

\section{Revista Docência e Cibercultura}

CAMPOS, S.R.L; TESKE, O. (orgs.) Letramento e Minorias. Porto Alegre: Editora Mediação, 2002. p. 110-119.

COSTA, M. T. M de S; SILVA, D. N. H; SOUZA, F. F. Corpo, atividades criadoras e letramento. São Paulo, Summus, 2013.

FANTI, M. da G. C. A linguagem em Bakhtin: pontos e pespontos. Veredas-Revista de Estudos Linguísticos, v. 7, n. 1-2, 2003.

FREITAS, M. T. de A. A abordagem sócio-histórica como orientadora da pesquisa qualitativa. Cadernos de pesquisa, n.1, p.21-39, 2002.GOÉS, M. C. R, de. A abordagem microgenética na raiz histórico-cultural: uma perspectiva para o estudo da constituição da subjetividade. CEDES, n.50, 2000.

LACERDA, C. B. F. de; SANTOS, L. F. dos; LODI, A. C. B.; GURGEL, T. Educação inclusiva bilíngue par alunos surdos: pesquisa e ação em uma rede pública de ensino (Orgs) Escola e Diferença: caminhos para educação bilíngue de surdos. São Carlos: EdUFSCar, 2016. p 13-28.

LEBEDEFF, T. R. Aprendendo "a ler" com outros olhos: relatos de oficinas de letramento visual com professores surdos. Cadernos de Educação (UFPel), v. 36, p. 175-196, 2010.

MOURA, M. C. de. Surdez e linguagem. LACERDA, C. B. F. de; SANTOS, L. F. dos. (Org.) Tenho um aluno surdo, e agora? Introdução à Libras e educação de surdos. São Carlos: edufscar, 2013. p. $13-26$.

NUNES, C; MADUREIRA, I. Desenho Universal para a Aprendizagem: construindo práticas pedagógicas inclusivas. Lisboa. 2015. p. 126 - 143.

PLETSCH, M. D; SOUZA, F. F. de; ORLEANS, L. F. A diferenciação curricular e o desenho universal na aprendizagem como princípios para a inclusão escolar. Revista Educação e Cultura Contemporânea, v. 14, n. 35, p. 264-281, 2017.

PLETSCH, M. D. Desenho Universal para a Aprendizagem: Implementação e avaliação do Protocolo do Livro Digital. Projeto de desenvolvimento. Nova Iguaçu, UFRRJ, 2017.

SKLIAR, C. Perspectivas políticas e pedagógicas da educação bilíngue para surdos. In: SILVA, Shirley; VIZIM, Marli. Educação Especial: múltiplas leituras e diferentes significados. Campinas: Mercado de Letras/ALB, 2001. p. 85-110.

SOUZA, F. F. de. Políticas de educação inclusiva: análise das condições de desenvolvimento 


\section{Revista Docência e Cibercultura}

dos alunos com deficiência na instituição escolar: Flavia Faissal de Souza. 2013. Tese (Doutorado em educação) - Universidade Estadual de Campinas, 2013.

SOUZA, F. F. de. O corpo dança: com(tra)dições e possibilidades de sujeitos afásicos. 2001. Dissertação (Mestrado em educação) - Universidade Estadual de Campinas, Campinas, São Paulo.

SKLIAR, C. A surdez: um olhar sobre as diferenças. Porto Alegre: Mediação, 1998.

TRIPP, D. Pesquisa-ação: uma introdução metodológica. São Paulo: Educação e Pesquisa, v.31, n.3, p. 443-466, 2005.

VASCONCELLOS, A. L. C. de. O papel do tradutor/interprete de Libras e as reflexões entre o TILS e o surdo no processo tradutório: um debate crítico sobre a inclusão/exclusão, subalternidade e amizade. In: BARROS, A. L. de. E. C. de; CALIXTO, H. R. da. S; NEGREIROS, K. A. de. Libras em diálogo: interfaces com tradução e interpretação. Campinas, SP: Pontes Editores, 2017.

TAVEIRA, C. C. A produção de artefatos visuais no campo da surdez: percursos de pesquisa e chaves de leitura. Rio de Janeiro: INES, Revista fórum, jun - dez, 2015.

VIGOTSKI, L. S. Pensamento e Linguagem. Rio de Janeiro: Martins Fontes, 1998. 